\title{
The Economic Impact of Junkanoo in The Bahamas
}

\section{Nicolette Bethel \\ The College of The Bahamas ${ }^{1}$}

ABSTRACT

In the 21 st century culture has moved from the periphery of economic activity to the centre and in the Caribbean, festivals are important generators of revenue. The Bahamian festival of Junkanoo resembles the carnivals of the Caribbean, but unlike them, no emphasis has yet been placed on the economic benefits of the festival. This paper summarizes the findings of a longterm study of the economic impact of Junkanoo. While the investment in Junkanoo is in excess of $\$ 18$ million, expenses currently outweigh revenue. Despite high tourist arrivals, the connection between Junkanoo and tourism is weak. However, the contribution of Junkanoo to the wider economy may share some similarities with that of festival tourism elsewhere in the Caribbean. Our findings demonstrated that Junkanoo generates employment and creates linkages among otherwise unrelated industries. It also has a spillover effect on the wider economy, such as fabric stores, TV cable stations and individual vendors. The current situation sees this investment as fuelling economic activity for various enterprises outside the Junkanoo community, but not so commonly within.

\section{INTRODUCTION}

In 2008, the United Nations Conference on Trade and Development (UNCTAD), in conjunction with the United Nations Development Programme, for the first time, published a study on the "creative industries" which proposed that "the interface among creativity, culture, economics and technology, as expressed in the ability to create and circulate intellectual capital, has the potential to generate income, jobs and export earnings while at the same time promoting social inclusion, cultural diversity and human development" (2008, p. iii). Two years later, a follow-up report argued that "world trade in creative goods and services remained relatively robust at a time when overall levels of international trade fell" (2010, p. xv), thus supporting the theory that "creativity, knowledge, culture, and technology can be drivers of job creation [and] innovation" (2010, p. Xv). This is inspite of the fact that:

...in 2008, the eruption of the world financial and economic crisis provoked a drop in global demand and a contraction of 12 percent in international trade. However,

${ }^{1}$ Nicolette Bethel, Assistant Professor, School of Social Sciences, College of The Bahamas. P.O. Box N-4912, Nassau, Bahamas

E-mail: nicolette.bethel@cob.edu.bs

Acknowledgements: The author is grateful to the students from SOS 200 at the College of The Bahamas, for their input and participation in this study. This article could not have been possible without their assistance. The study was funded in part with a research grant from the Office of Research, Graduate Programmes and International Relations of The College of The Bahamas

APA reference: Bethel, N. (2014). The economic impact of Junkanoo in The Bahamas. The International Journal of Bahamian Studies, 20(1), 13-26. Retrieved from http://journals.sfu.ca/cob/index.php/files/article/view/206/270

(c) N. Bethel, 2014. Journal compilation (c) The International Journal of Bahamian Studies, 2014 
world exports of creative goods and services continued to grow, reaching $\$ 592$ billion in 2008 - more than double their 2002 level, indicating an annual growth rate of 14 percent over six consecutive years. This is a confirmation that the creative industries hold great potential for developing countries that seek to diversify their economies and leapfrog into one of the most dynamic sectors of the world economy (UNCTAD \& UNDP, 2010, p. xxiii).

Closer to home, whole economies (Barbados, for example, National Task Force on Cultural Industries, 2004) have been restructured to benefit from the creative industries. The Bahamas, on the other hand, has only recently moved to take advantage of this shift in the global economic landscape.

Among the opportunities offered by the creative economy is the development of cultural tourism. The 2010 UNCTAD report observes, "Globally, tourism is a $\$ 3$ billion-aday business [which] is the main source of foreign exchange for one-third of developing countries and one-half of least developed countries, where it accounts for up to 40 per cent of GDP", and, further, that

the cultural sector contributes to tourism through the demand for visits to cultural heritage sites, festivals, museums and galleries as well as music, dance, theatre, opera performances, etc. More generally, the cultural ambience and traditions of different locations can be an attraction for tourists, especially for those classified as 'cultural tourists' who are more discriminating and culturally aware than the so-called mass tourists (p. 21).

In The Bahamas, however, the tourist product remains focused on resort and cruise ship visitors, with an emphasis on sun, sand, sea, and casinos. Cleare (2007) does not even mention cultural or creative factors in the index (pp. 622-623) of her history of tourism in The Bahamas. They are similarly absent from the Bahamian tourism product.

\section{Festival and Event Tourism Studies}

Festival tourism is a critical sub-set of the overall cultural economy matrix (Throsby, 1994), which has gained prominence over the past 20 years (Getz, 2005, 2007, 2010; Nurse, 1999, 2002, 2003; Picard \& Robinson, 2006: Yeoman, Robertson, Ali-Knight, Drummond, \& McMahon-Beattie, 2004). Events and festivals have been demonstrated to be loci of economic activity, and as a result have received considerable investment from cities, regions and countries seeking revitalization or increased revenue (Andersson \& Getz, 2008; Carlsen, 2004; Clarke \& Hoaas, 2007; Finkel, 2009; Quinn, 2005, 2006). They are important attractors of tourism and are popularly assumed to increase economic activity in the place where they are held-so much so that they have become important foci of economic studies.

\section{The Caribbean Festival Economy}

According to the Inter-American Development Bank "throughout the Caribbean festival tourism is gaining prominence in the tourism calendar" (Nurse, 2003, p. i). Moreover, such tourism "has experienced significant growth in the last decade as tourist planners have come to recognize the demand-pull of the arts, popular music, entertainment and themed events" (Nurse, 2003, p. i). Caribbean festivals, moreover, are critical parts of the Caribbean diaspora. There are more than 70 Caribbeanstyle carnivals in Europe and North America, the most prominent of which attract millions of attendees. For instance, the Labor Day Carnival in New York attracts in excess of 3.5 million people, Notting Hill in London attracts 1.5 million, Caribana in Toronto attracts 1.1 million (Nurse et al., 2007, p. 173). 


\section{The festival of Junkanoo}

The Bahamian festival of Junkanoo resembles the carnivals of the Caribbean (Bethel, 2000). Although Junkanoo takes place during the Christmas season - the two major competitive parades occur on Boxing Day (December 26) and New Year's Day-it is a major street parade that fulfills many of the social and symbolic functions of Caribbean carnivals elsewhere.

In contrast to other Caribbean carnivals, however, Junkanoo organizers and practitioners have been slow to capitalize on the economic potential of the festival, and scholars have focused on the political and symbolic nature of the parade rather than the economic. Although tickets are sold for the parades, they are viewed as celebratory competitions rather than engines of economic activity. Ministry of Tourism officials believe that there is no need to promote Junkanoo to tourists, as during the Christmas season hotels are full (V. Vanderpool-Wallace, personal communication, November 2003). The majority of Junkanoo tickets are sold to Bahamians, not tourists. Junkanoo is not officially exported, although Junkanoo groups appear at international diasporic carnivals as well as other festivals such as the Smithsonian Folklife Festival in Washington, DC. Despite considerable discussion and still-born projects, none of the current government investment in Junkanoo seeks to build economic capacity for its practitioners. In June 2013, for the first time, Prime Minister Perry Christie announced the incorporation in the 2013-2014 budget the sum of \$1 million to go towards the boosting of Bahamian cultural industries (Christie, 2013); but this money was earmarked to create a Bahamian Mardi Gras or Carnival and was not focused specifically on Junkanoo. Unlike cultural festivals throughout the Caribbean, Junkanoo remains largely outside national discussion of economic activity and potential.

\section{Economic impact of Junkanoo}

Beginning in January 2009, a study was inaugurated with the general research question: What is the economic impact of Junkanoo? Students at the College of The Bahamas were assigned the task of investigating various elements of this question. The long-term goal was to estimate the economic impact of Junkanoo on The Bahamas.

\section{Methodology: Processes and challenges}

Researchers in event management have indicated the complex nature of the collection of data regarding events (Carlsen, 2004; Getz, 2005, 2007; Hesmondhalgh \& Pratt, 2005; Mangia, Canonico, Toraldo \& Mercurio, 2011; Tull, 2012). As Getz (2005), Nurse (2004), and Picard and Robinson (2006) have argued, the core of the cultural event is experiential and unique. This renders it difficult to measure impacts in purely concrete terms. Impact assessments of festivals need to be multi-faceted (Getz, 2005, 2007). This is particularly true in the Caribbean (Burke, 2007; Nurse, 2002, 2004), and even more so in The Bahamas, where the recognition of the cultural value of the arts is a very recent concept.

This particular study faced a series of methodological challenges. Initial attempts to use the methods modelled for the Caribbean by Nurse et al. (2007), relying on available official statistics and information gathered by stakeholder agencies, revealed that data about Junkanoo are not systematically collected by any agency. It was clear that the study would have to generate its own baseline data.

The methodology developed in an ad hoc fashion as these baseline data were sought. The initial studies conducted were all quantitative. Although not ideal, convenience samples were found to yield the most results. This is not unusual for The Bahamas, as noted by Fielding and Samuels (2002) and 
Vanderpool and Fielding (2003). Anecdotal and observational evidence suggested that the majority of the attendees at Junkanoo were local, and so the first surveys targeted Bahamians. The first data sets collected were skewed towards females between the ages of 18 and 25 with a post-secondary education.

In the absence of ready access to the visitor exit surveys regularly conducted by the Bahamas Ministry of Tourism (and recognizing, further, that those surveys asked no questions regarding cultural activity), College of the Bahamas students asked tourists about their knowledge of and attendance at Junkanoo. Exit surveys were also conducted to determine attendance and consumption patterns at two other local festivals, the CariFringe multi-arts festival of October 2010 and the Shakespeare in Paradise theatre festivals of October 2010 and 2011. This quantitative approach was augmented by interviews, ethnographies and direct observation.

\section{This study}

The findings presented in this paper comprise the results of 13 studies conducted between January 2009 and May 2013.

1. Spring 2009: Survey of college students about their consumption of Junkanoo

1a. Qualitative studies aimed at identifying the potential benefits of Junkanoo

2. Fall 2009: Survey of attitudes and practices of the general public regarding Junkanoo

3. Boxing Day 2009/New Year's Day 2010:

Crowd counting at Junkanoo parades

4. Spring 2010: Survey of tourists regarding their familiarity with Junkanoo

4a. Interviews and focus group studies about the promotion and marketing of Junkanoo 5. Fall 2010: Baseline survey of Bahamians' consumption of other Bahamian cultural industries, such as the multi-arts festival Carifringe and the theatre festival Shakespeare in Paradise

6. Spring 2011: Secondary analysis of the Fall 2009 survey 6a. Interviews with stakeholders regarding the economic impact of Junkanoo

7. Fall 2011: Follow-up survey of Bahamians' consumption of Shakespeare in Paradise

7a. Ethnographic studies of specified

Junkanoo shacks

8. Spring 2012: Secondary analysis of data from the Fall 2009 survey

9. Spring 2013: Study of impact of Junkanoo administration on economic effectiveness of Junkanoo

Both quantitative and qualitative methods were employed as appropriate. Doublecounting may have been an issue throughout the study, as students may have surveyed the same individuals more than once, or may have recounted the same individuals more than once in the crowd-observation exercise, or Junkanoo groups may have double-reported sources of income.

\section{Quantitative Methods: Surveys}

Surveys were conducted on:

1. College students' participation in, attendance at, and watching of Junkanoo

2. The wider community's overall satisfaction with the Junkanoo parades

3. Tourists' attendance at and awareness of Junkanoo

4. The festival-going public's attendance at and expenditures on festivals other than Junkanoo

Students worked together to design the surveys. In most cases, basic demographic information was sought from survey participants. In the surveys of the festivalgoing public, respondents were asked for their educational level.

Close-ended questions were asked regarding levels of expenditure on the various festivals, from the purchasing of tickets and merchandise to the actual investment in participating in the festivals. Some openended questions were included to seek further and more specific information or to elicit additional comments. 
In every case convenience samples were used. Scholars have argued that in The Bahamas attempts at obtaining random samples generally yield poor returns; neither the postal survey nor the random calling methods have proven cost- or time-efficient (Fielding \& Samuels, 2002; Vanderpool \& Fielding, 2003). In every case but two, the samples are skewed towards a young, college-educated category of respondents. More interestingly, all of the samples are also skewed towards female respondents.

Attempts were made to broaden the responding public through the use of online surveys using SurveyMonkey ${ }^{\mathrm{TM}}$. This had the effect of increasing the base of respondents in the 25-34 age range, but had the additional effect of biasing the sample towards those people who had the means to get online. In most cases, surveys were administered face to face.

Respondents had to be aged 18 or over, and give verbal consent to participate in the paper surveys. On-line surveys included a consent page which allowed those who agreed to the terms of the study to enter the survey. In each format, participation was anonymous and respondents had the freedom not to answer any question that made them uncomfortable.

\section{Crowd counting}

An unobtrusive observation of actual attendance at the Junkanoo parades was conducted during the 2009-2010 season. For this study, small groups of researchers (seven on December 26, 2009 and six on January 1, 2010) counted the crowds.

Counters identified a section of seats, counted the number of people in an individual row of seats and multiplied that number by the number of occupied rows in the section. This exercise was repeated each hour. Demographic information of the spectators was recorded, based on observation, as well as the section counted, the time of the count, and the name of the Junkanoo group passing that section at that time.

\section{Qualitative Methods}

These methods included open-ended interviews of participants, administrators and supporters of the parades, focus groups, and mini-ethnographies of Junkanoo shacks:

1. Interviews with stakeholders during the spring of 2009

2. Focus groups with organizers and administrators in the spring of 2010

3 . In-depth interviews with selected stakeholders in the spring of 2011.

4. In the fall of 2011, 15 students conducted ethnographies in selected Junkanoo shacks. Six Junkanoo groups permitted students to visit and hang out in their shacks. These ethnographic studies helped to fill in gaps that had hitherto existed.

5. In-depth interviews with key informants in the spring of 2013. The stakeholders were selected if they were experts in the expenditures on Junkanoo-Junkanoo leaders and representatives of Junkanoo sponsors; in revenue collection - managers and owners of stores specializing in Junkanoo materials; or as representatives of businesses affected by the Junkanoo parades.

Ethical considerations for the qualitative studies included anonymity, confidentiality, and harm to participants. In the beginning, there was resistance to their questions, but as the study developed, students found more willingness among Junkanoo practitioners to share their craft.

The cost of Junkanoo is shared among the government of The Bahamas, the Junkanoo Corporation of New Providence, Junkanoo groups, corporate sponsors, and individual Junkanoo practitioners. The primary funding agency in the government is the Junkanoo Unit of the Ministry of Youth, Sports and Culture.

Since 2001, the Ministry of Youth, Sports and Culture has spent an average of $\$ 1,350,000$ 
per annum. This includes the cost of preparing and administering the parade route, and the seed funding provided to all Junkanoo groups throughout The Bahamas. In New Providence, each A Division group receives
$\$ 8,000$ in start-up funding, and each B Division group receives $\$ 4,000$ (See below for definitions for A Division and B Division groups). Table 1 provides an extensive list of costs associated with the parades in 2005/06.

\section{Table 1}

Estimated expenses of the three major Junkanoo parades, 2005/06

\begin{tabular}{lr}
\hline Junkanoo Expenses 2005-2006 & \\
\hline Seed funding & $\$ 300,000.00$ \\
Hurricane relief to Junkanoo groups & $\$ 10,000.00$ \\
Family Island prize money and committee expenses & $\$ 65,000.00$ \\
Junior Junkanoo parade expenses and awards & $\$ 105,000.00$ \\
Booklets, supplies, meetings, presentations, workshops & $\$ 6,000.00$ \\
Operational expenses for Junkanoo Corporation (New Providence) & $\$ 10,000.00$ \\
Printing of score cards for parades & $\$ 8,000.00$ \\
Rental of tents for concession stands & $\$ 10,000.00$ \\
Set-up, clean-up, clearing up and assembling of parade route & $\$ 18,000.00$ \\
Promotions, prejudging, entry drawing and announcement of results & $\$ 5,000.00$ \\
Electrification of tents and other parade areas & $\$ 12,000.00$ \\
Rental of visual, sound and communication equipment & $\$ 20,000.00$ \\
Security and fencing of parade route and sites & $\$ 15,000.00$ \\
Porta-toilets, workers' tents, tables, chairs & $\$ 15,000.00$ \\
Identification, vesting, workers' attire & $\$ 18,000.00$ \\
Refreshments for judges, workers and police & $\$ 40,000.00$ \\
Advertising, promotion and marketing costs & $\$ 20,000.00$ \\
Charges and fees for tallying judges' scoring & $\$ 5,000.00$ \\
Awards Presentation and Banquet and expenses & $\$ 35,000.00$ \\
Printing of Junkanoo Souvenir booklet & $\$ 5,000.00$ \\
Liability insurance & $\$ 10,000.00$ \\
Complimentary tickets & $\$ 35,000.00$ \\
New Providence Prize Money & $\$ 400,000.00$ \\
TOTAL & $\$ 1,167,000.00$ \\
\hline Bleachers and ticketing & \\
Bleachers & $\$ 480,000.00$ \\
Ticketing & $\$ 40,000.00$ \\
Marshalling & $\$ 20,000.00$ \\
\hline & $\$ 540,000.00$ \\
\hline TOTAL EXPENSES & $\$ 1,707,000.00$ \\
\hline
\end{tabular}

Based upon the official expenses available from the Ministry of Youth, Sports and Culture, it is clear that, conservatively, we can estimate the annual cost to the public of Junkanoo at over $\$ 2$ million per year (Table
2). However, this does not include the loss of tax revenue due to the duty-free status of materials used for Junkanoo costumes and instruments used by Junkanoo musicians. 
Table 2

Direct profit/loss of Junkanoo to the Ministry of Youth, Sports and Culture, 2001-2006

\begin{tabular}{|c|r|r|r|r|r|r|r|}
\hline Year & $\begin{array}{c}\text { Seed and } \\
\text { prize money }\end{array}$ & $\begin{array}{c}\text { Parade } \\
\text { expenses }\end{array}$ & $\begin{array}{c}\text { Bleacher } \\
\text { expenses }\end{array}$ & $\begin{array}{c}\text { Misc. } \\
\text { expenses }\end{array}$ & Total expenses & $\begin{array}{c}\text { Bleacher } \\
\text { revenue }\end{array}$ & \multicolumn{1}{c|}{ Profit/loss } \\
\hline $2001-2002$ & $\$ 363,700$ & $\$ 300,000$ & $\$ 202,872$ & $\$ 48,296$ & $\$ 914,868$ & $\$ 300,000$ & $-\$ 614,868$ \\
\hline $2002-2003$ & $\$ 544,900$ & $\$ 300,000$ & $\$ 1,072,560$ & $\$ 41,155$ & $\$ 1,958,615$ & $\$ 672,279$ & $-\$ 1,286,336$ \\
\hline $2003-2004$ & $\$ 765,000$ & $\$ 320,000$ & $\$ 0.00$ & $\$ 30,000$ & $\$ 1,115,000$ & $\$ 72,000$ & $-\$ 1,043,000$ \\
\hline $2004-2005$ & $\$ 765,000$ & $\$ 350,000$ & $\$ 0.00$ & $\$ 45,000$ & $\$ 1,160,000$ & $\$ 68,000$ & $-\$ 1,092,000$ \\
\hline $2005-2006$ & $\$ 765,000$ & $\$ 357,000$ & $\$ 540,000$ & $\$ 45,000$ & $\$ 1,707,000$ & $\$ 700,000$ & $-\$ 1,007,000$ \\
\hline
\end{tabular}

\section{Cost to Junkanoo Corporation}

Since 2008 the Junkanoo Corporation New Providence has taken responsibility for administering the parades and awarding the
$\$ 350,000$ in prize money for the groups. A full listing of its costs is given in Table 3 (S. Ferguson, personal communication, June 7 , 2013).

\section{Table 3}

Estimated cost of a Junkanoo season.

GOVERNMENT

Ministry of Youth, Sports and Culture

$\$ 1,350,000.00$

Other agencies

$\$ 650,000.00$

Total

$\$ 2,000,000.00$

Junkanoo Corporation New Providence

Prize money

$\$ 350,000.00$

Professional fees (accounting \& legal)

$\$ 23,000.00$

Ticketing

$\$ 55,000.00$

PMT \& parade personnel on Bay Street (meals \& stipends)

$\$ 20,000.00$

Junkanoo Corporation New Providence stipends

$\$ 25,000.00$

Awards banquet

$\$ 42,000.00$

Total Expenses

$\$ 515,000.00$

\begin{tabular}{|c|c|c|c|}
\hline SHACKS & \multicolumn{2}{|l|}{ Estimated investment per shack } & \\
\hline Extra materials & \multicolumn{2}{|c|}{$\$ 15,000.00$} & \\
\hline Shack upkeep & \multicolumn{2}{|c|}{$\$ 10,000.00$} & \\
\hline Total & $\$ 25,000.00$ & 32 & $\$ 800,000.00$ \\
\hline LABOUR & Cost per participant & No. of participants & \\
\hline Total av. wage per participant & & 3,200 & $\$ 10,880,000.00$ \\
\hline GROUP COSTS & Av. cost per annum & No. of groups & \\
\hline A Division & $\$ 150,000.00$ & 6 & $\$ 900,000.00$ \\
\hline \multirow[t]{2}{*}{ B Division } & $\$ 30,000.00$ & 8 & $\$ 240,000.00$ \\
\hline & & & $\$ 1,140,000.00$ \\
\hline PERSONAL INVESTMENT & Unit & Number of participants & \\
\hline Per season & $\$ 1,000.00$ & 3,200 & $\$ 3,200,000.00$ \\
\hline Grand total & & & $\$ 18,535,000.00$ \\
\hline
\end{tabular}




\section{Cost to groups}

Groups compete in various divisions differentiated primarily by size (specific distinctions may be found in the JCNP Rules 2012 available at http://jenp.net/en/aboutjenp/articles) and designated as $\mathrm{A}$ or $\mathrm{B}$ Division groups. Group size is a major factor governing cost for parades. Interviews with group leaders in 2009 revealed that while on average the annual cost of two A Division group performances was $\$ 150,000$, the actual cost per group could range from $\$ 60,000$ $\$ 80,000$ for a small A Division group to between $\$ 250,000$ and $\$ 350,000$ for a larger one; a B Division can spend in the region of $\$ 30,000$.

\section{Cost by group}

In 2013, five group leaders shared information about their costs. The median amount spent on materials (such as rods, crepe paper, feathers etc.) was $\$ 60,000$ (range $\$ 50,000$ $\$ 350,000)$ and median amount spent on operating the shack was $\$ 10,000$ (range $\$ 1,800-\$ 30,000$ ).

\section{Cost to groups}

In 2012 there were of six A Division groups and eight $\mathrm{B}$ Division groups, so the total estimated cost to the groups would be about $\$ 1,140,000$.

\section{Cost within individual shacks}

In most cases, group administrators purchase materials (such as crepe paper, styrofoam, aluminum rods and cardboard required for basic construction and pasting of the costumes) in bulk and distribute them among the group members. Once the corporate materials are received, each member adds to them as needed to produce the costumes. This expense is difficult to measure. These smaller-scale investments may not even be noted by the practitioners themselves. The ethnographies conducted in Junkanoo shacks attempted to ascertain these often personal expenses. Items bought were numerous, ranging from decorative mirrors $(\$ 1.99$ for $10)$ to construction rods ( $\$ 500$ for 60 pieces). The assembling of the thousands of individual pieces that make a Junkanoo costume is labour-intensive. While some individuals make a living from Junkanoo, the majority of participants invest their time for no remuneration.

In one shack, the majority of workers had jobs, and worked on their costumes in their off hours, including lunch times. Using the cost per hour of the individuals' average work pay, researchers estimated that cost ranged from $\$ 48$ per week at the very lowest scale (a student spending eight hours per week in the shack) to upwards of $\$ 300$ per week.

Using an hourly wage of $\$ 10$ per hour per Junkanoo practitioner, and estimating the average amount of time per week spent in the chosen shack as 20 hours, we can calculate the cost of labour per practitioner at a modest \$200 per week. Assuming 17 weeks to prepare the costumes, the estimated cost of labour is at least $\$ 3,400$ per Junkanoo practitioner per season. That this is conservative is evidenced by the fact that, according to the Department of Statistics' Occupational Wage Survey (2008), the average hourly wage for Bahamians is $\$ 14$, and the average weekly wage is $\$ 527$ (p. 3). Further, it is evident that a 20 -hour work week is also conservative. The shack studied belonged to a B Division group, and studies carried out in shacks belonging to the A Division groups indicated that their members worked far longer than 20 hours per week-8 to 16 hours a day, seven days a week (depending on one's employment status) during the peak period. Assuming that an A Divison group may average 500 people, and a B Division group 100 people, we conservatively estimate the labour as $\$ 10,880,000$ per annum in New Providence alone. 


\section{Personal investment}

In one group $65 \%$ of the respondents would spend whatever was necessary and $35 \%$ were willing to spend up to $\$ 1,500$ on their costumes. Those people who set limits on their Junkanoo expenditure were willing to use 3-7 weeks' pay for their costumes.

\section{Sponsorship}

Sponsorship also provides individual groups with funding towards their preparations. Five groups reported obtaining a median of $\$ 55,000$ in sponsorship (range $\$ 25,000$ $\$ 180,000)$. Clearly, this represents only a small fraction of the cost of preparing for a parade.

\section{Overall Economic Cost of Junkanoo}

When we assemble these often conservative costs, we can estimate the overall cost of Junkanoo at \$18-19 million, based upon the figures in Table 3.

\section{Revenues generated}

Studies of festivals throughout the Caribbean and around the world indicate that such events generate returns above the investments made (UNCTAD 2008, 2010). In The Bahamas, however, emphasis has traditionally been placed more on financing the Junkanoo parade than on earning revenue from it. Our findings regarding revenue are sketchy.

Our results speak more to potential revenue from Junkanoo than to actual revenue. Surveys we have conducted in this area have focused on the following:

1. Junkanoo audiences' willingness to pay to attend Junkanoo,

2. Preferred price points for tickets to attend Junkanoo and other cultural activities

3. Who attends Junkanoo

4. What Junkanoo audiences like about Junkanoo

5. What keeps audiences from attending Junkanoo in person

The primary source of revenue that goes directly into the parade comes from the sale of tickets to see the three main parades-Junior Junkanoo, Boxing Day and New Year's Day.

\section{Tickets}

Tickets for Junkanoo seating were first sold during the 1980s. This innovation was instituted in an attempt to offset costs. At that time, wooden benches were set up at strategic locations on Bay Street and tickets sold at nominal prices to those who wanted to sit during parades.

Over the next 15 to 20 years the numbers of bleachers increased until the 2001-2002 season, and the sale of tickets helped offset the cost of prizes; that season, bleacher revenue was calculated at $\$ 300,000$.

In 2002, seating capacity was increased to 10,000 seats and ticket prices were raised to a maximum of $\$ 75$ for premium seating. During the 2002-2003 season, the bleacher revenue from the main parades reached $\$ 500,000$.

Between 2003 and 2005, C-Cube Seating bore the cost of the aluminum bleachers and ticketing and also collected the revenue, giving the government $10 \%$ of the gross take. In 2003-2004, revenues remitted to the government totaled $\$ 72,000$, suggesting that bleacher revenue was $\$ 720,000$. In 20042005 , the money remitted to the government totaled $\$ 68,000$, suggesting that bleacher revenue was $\$ 680,000$.

Ticket prices vary, depending on location on the parade route, and have varied even more over time since 2002. When the seats were introduced, premium seating in the Rawson Parliament Square area was priced between $\$ 60$ and $\$ 75$ per seat (2002-2005), while less preferred venues could be purchased for $\$ 20$. In 2007-2008, the premium ticket prices were reduced and ranged from $\$ 50$ to $\$ 10$. In the 2008-2009 season, ticket prices were further reduced to $\$ 45$ and $\$ 5$. These represent the prices currently, with a median price of $\$ 25$ for the senior parades (and $\$ 15$ for Junior 
Junkanoo). However, these reduced prices have been accompanied by a reduction in the demand for tickets, particularly for the New Year's Day parade (Cleare, 2011, Ferguson, 2013, Thompson, 2012).

\section{Attendance at Junkanoo}

While most (66\% in the 2009 survey) indicate a willingness to pay for Junkanoo tickets, a majority $(54 \%)$ had never paid to attend Junkanoo. This result may have been skewed by the fact that $75 \%$ of the respondents were between the ages 18-25; nevertheless, it is an interesting response.

When asked to rank what respondents were willing to purchase tickets for, they ranked Junkanoo seventh of 10 named events, holding a higher spot than sporting events, music festivals, and film festivals.

When asked what was the most they would be willing to pay for Junkanoo tickets, $30 \%$ of respondents were willing to pay up to $\$ 10$, $37 \%$ were willing to pay up to $\$ 25,25 \%$ were willing to pay up to $\$ 50$, and $8 \%$ were willing to pay as much as $\$ 100$ for Junkanoo tickets. The most frequent maximum price point for Junkanoo tickets was $\$ 25$, a figure which corresponds well to the maximum price point for tickets to see other local performances, as indicated by audiences at Shakespeare in Paradise in October 2010 and October 2011.

\section{Crowd counting: estimated attendance}

Estimated occupancy on Bay Street on Boxing Day 2009 over the period 3:30 am to 6:30 am was 4,752 persons. Numbers were not collected for Shirley Street on Boxing Day 2009. A rough estimate of the size of the crowd for the whole evening can be calculated by multiplying this figure by 1.5 for a total of about 7,000 .

Estimated occupancy for the whole route on New Year's Day 2010 over the same period was 5,835 persons. Occupancy for New Year's Day 2010 was estimated by counting individuals occupying a random row of bleachers - or standing on the roadside - and multiplying that figure by the average number of rows for the whole parade route. Overall, then, the occupancy of Junkanoo for the 20092010 season can be estimated to have been about 13,000 .

Given that the median price for tickets is $\$ 25$ (tickets are priced at $\$ 5, \$ 15, \$ 35$ and $\$ 45$ ), revenue for the two parades can be estimated at being approximately $\$ 325,000$ for the 2009-2010 season, or $2 \%$ of the cost of putting on the parades. These figures are rough estimates, but give some idea of what revenue from the two main Junkanoo parades might be. What is more, during the 20122013 season, total seating available on the route was 17,000 seats; this suggests that occupancy overall at Junkanoo can be estimated to be $76 \%$. It is instructive to note that the occupancy of events such as Shakespeare in Paradise is some 60-65\%; Junkanoo, despite all the challenges, is a popular festival.

\section{Junkanoo and tourism}

Historically, the more difficult seats to sell for Junkanoo are for the New Year's Day parade. At the same time, the Christmas/New Year season is the peak season for tourism. Hotels are usually operating at $100 \%$ occupancy, and cruise ships are often in port on New Year's Eve. Given the potential of selling tickets to tourists, a study of 197 tourists in FebruaryApril 2010 indicated that although $35 \%$ of the tourists had heard of Junkanoo, only $9 \%$ of them had attended the parades.

\section{Concessions}

Secondary sources of revenue come from nominal charges made to persons such as photographers and the press in general. These charges are collected by the Ministry of Youth, Sports and Culture and do not go to the Junkanoo Corporation New Providence. Current figures for these charges are not available. 
Fees are paid by vendors for concession stands along the route. These were $\$ 100$ per parade or $\$ 200$ per season between 2003 and 2008. During the 2009-2010 season, approximately 20 such booths were counted in Parliament Street. These fees are paid to the Ministry of Youth, Sports and Culture.

\section{Support services}

Vendors at the parades typically sell refreshments. In 2009, one such vendor made $\$ 5,068$ on Boxing Day and $\$ 4,345$ on New Year's Day, a total of $\$ 9,413$. Given that in 2004 the average annual wage in The Bahamas stood at $\$ 23,751$, this represents about four to five months' salary.

Stores specializing in Junkanoo supplies can increase their sales by some $30 \%-40 \%$ prior to the parades. Welders are required to make bells, and music stores also provide instruments. Similarly, Cable Bahamas earned some $\$ 97,632$ during its coverage of Junkanoo in the 2008-2009 season from advertising.

\section{Other}

Other sources of revenue include in-kind exchanges, in particular the supplying of Junkanoo groups with basic construction material such as contact cement, glue, brushes and so on, a regular commitment of hardware companies such as Commonwealth Building Supplies (S. Ferguson, personal communication, September 2011). Junkanoo groups also actively raise funds year-round by holding cook-outs, selling t-shirts, and from food and beverages sold at Junkanoo practices. Major groups also make recordings of Junkanoo music and the sales from their recordings bring in revenue.

Junkanoo practices, particularly those which take place in the communities that surround the shacks, generate economic activity for those communities as well as for the groups. In-kind support is also given by the families and friends of the Junkanoo artists, who assist with bills for the shacks, food for the workers in the shack, and other small ways difficult to enumerate.

\section{Discussion}

In their studies of festivals throughout the Caribbean, Nurse et al. (2007) indicate that while the investment in such festivals must be significant in order for them to succeed financially (Nurse, 2002; Burke, 2007), there is a high return on that investment when it is made. As they observe:

The benefit-to-cost analysis indicates that most festivals have a healthy yield or return on investment. The festival with the highest estimated benefit-to-cost ratio is that of the St. Lucia Jazz Festival with 9.1:1. Trinidad Carnival is ranked second with a ratio of 7:1. Barbados Crop Over generated a ratio of 2.4:1. These ratios, especially of St. Lucia and Trinidad, appear to be very competitive when compared with top international festivals like the Edinburgh Arts Festival, which generated a benefit-to-cost ratio of 11:1. (Nurse et al. 2007, pp. 178-9).

\section{Table 4}

Festival Tourism Economic Impact

\begin{tabular}{|l|c|c|c|c|c|c|c|c|c|}
\hline & 1997 & 1998 & 1999 & 2000 & 2001 & 2002 & 2003 & 2004 & 2005 \\
\hline \multicolumn{8}{|c|}{ Trinidad Carnival } \\
\hline Festival arrivals & 27,414 & 35,665 & 34,907 & 42,646 & 35,221 & 33,487 & 38,537 & 40,455 & 40,555 \\
\hline Visitor expenditures (US\$m) & 10.2 & 14.0 & 18.1 & 17.7 & 21.4 & 22.7 & 26.2 & 27.5 & \\
\hline \multicolumn{8}{|c|}{ St. Lucia Jazz } \\
\hline Festival arrivals & n.a. & 9,929 & 9,909 & 11,041 & 8,421 & 11,203 & 12,164 & 12,553 & \\
\hline Visitor expenditures (US\$m) & n.a. & 14.1 & 13.9 & 14.8 & 12.0 & 12.5 & 17.3 & & \\
\hline
\end{tabular}

Note: Table from Nurse et al. (2007), p. 176. 
In The Bahamas, our findings suggest three things. First, the link between Junkanoo and tourism is weak. Junkanoo is not actively promoted to tourists. As our findings suggest, only a minority of tourists are aware of its existence, and an even smaller percentage of them had attended the festival.

This peculiarity of the Bahamian situation leads us to our second observation: that expenses for Junkanoo currently outweigh revenue. One observation of note is the negative relationship between ticket prices and sales. This would appear to warrant further study as it impacts revenue. As we have seen, expenses come from every sector of society-government, corporations, foreign investors, small businesses and individuals. Moreover, we have shown that the largest single investment in Junkanoo comes from the participants themselves. However, our findings also indicate that the contribution of Junkanoo to the wider economy may share some similarities with that of festival tourism elsewhere in the Caribbean. While we cannot show that Junkanoo increases government tax receipts, we have demonstrated that, for some practitioners and their communities, it generates employment and creates linkages among otherwise unrelated industries. It also has a spillover effect on the wider economy, such as fabric stores, TV cable stations and individual vendors.

The current situation sees this investment as fuelling economic activity for various enterprises outside the Junkanoo community, but not so commonly within. What is more, the current structures in which Junkanoo operates suggest that Junkanoo is a means by which Bahamian currency leaves the country rather than as a means of attracting foreign exchange, as almost all of its composite materials are imported. Further study is required to gain better understanding of the revenues generated and who may be the ultimate beneficiaries.

And yet the Junkanoo community continues, every year, to make this investment. This suggests that the returns on that investment of approximately \$18 million in unwaged labour and personal contributions must be considered intangible by those who make the investment. It is noteworthy that the generally unpaid labour is the single largest component of the costs identified in Table 3.

When considered within the field of research on events and festivals, even heeding the cautions expressed by researchers such as García (2004) and Quinn (2005), among others, then, what is clear from this study is that the economic potential of Junkanoo remains untapped. While recent survey data indicate that Bahamians consider Junkanoo to be very important or essential to Bahamian national identity, the festival still struggles to attract the kind of investment that will generate the kinds of returns seen in festivals elsewhere. Despite the acknowledged limitations in attempting to estimate the cost and revenues associated with the nation's premier cultural events, we feel that this research for the first time starts to indicate the order of magnitude of producing Junkanoo. As such the figures will have implications for further initiatives to sustain and expand cultural activities in The Bahamas.

doi:10.1080/15470140802323801

Bahamas Department of Statistics. (2008). Occupational wage survey, 2007. Nassau, Bahamas: Bahamas Department of Statistics. Retrieved from

(c) N. Bethel, 2014. Journal compilation (c) The International Journal of Bahamian Studies, 2014 
http://statistics.bahamas.gov.bs/download/04 5942800.pdf

Bethel, N. (2000). Navigations: The fluidity of identity in the post-colonial Bahamas. (Unpublished doctoral dissertation). Cambridge, Eng: University of Cambridge.

Burke, S. (2007). Disjuncture and displacement: The evolution of the cultural policy regime in the Anglophone Caribbean. International Journal of Cultural Policy, 13(2), 169-184.

Carlsen, J. (2004). The economics and evaluation of festivals and events. In Yeoman, I., Robertson, M., Ali-Knight, J., Drummond, S., \& McMahon-Beattie, U. (Eds.) Festival and events management: An international arts and culture perspective (Kindle ed., pp. 240-253). Burlington, MA: Elsevier.

Clarke, G. D., \& Hoaas, D. J. (2007). Festival economics: the case of the Red River Revel. Tourism Economics: The Business and Finance of Tourism and Recreation, 13, 163-175.

Cleare, A. B. (2007). History of tourism in The Bahamas. Nassau, Bahamas: XLibris.

Christie, P. G. (2013). Commonwealth of The Bahamas 2013/14 budget communication. Retrieved from http://www.bahamas.gov.bs/wps/wcm/conne ct/42e1e3c7-c66a-4069-bf3634172639ef17/BUDGET+COMMUNICATI $\mathrm{ON}+290513+\mathrm{Combined}$.pdf?MOD=AJPER ES

Ferguson, S. (2013, January 3). [Interview]. ZNS News. Retrieved from http://www.znsbahamas.com/news.php?ID= 15130

Fielding, W. J., \& Samuels, D. (2002).

Preliminary observations on the telephone survey as a research tool in New Providence. The College of The Bahamas Research Journal 11, 4-10. Retrieved from http://journals.sfu.ca/cob/index.php/files/arti cle/view/41/70
Finkel, R. (2009). A picture of the contemporary combined arts festival landscape. Cultural Trends, 18, 3-21. doi:10.1080/09548960802651195

Getz, D. (2005). Event management and event tourism. (2nd ed.). New York, NY: Cognizant.

Getz, D. (2007). Event studies: Theory, research and policy for planned events. (Kindle ed.). Burlington, MA: Elsevier.

Getz, D. (2010). The nature and scope of festival studies. International Journal of Event Management Research, 5, 1-47. Retrieved from http://www.ijemr.org/docs/Vol5-1/Getz.pdf

Hesmondhalgh, D., \& Pratt, A. C. (2005). Cultural industries and cultural policy. International Journal of Cultural Policy, 11, 1-13. doi:10.1080/10286630500067598

Junkanoo Corporation New Providence. (2012). JCNP rules 2012. Retrieved from http://jcnp.net/en/about-jenp/articles

Mangia, G., Canonico, P., Toraldo, M. L., \& Mercurio, R. (2011). Assessing the socioeconomic impact of performing arts festivals: A new theoretical model. Journal of US-China Public Administration, 8(9), 1016-1031.

National Task Force on Cultural Industries. (2004). Policy paper to inform the propelling of Barbados' creative economy. Bridgetown, Barbados: Author.

Nurse, K. (1999). Globalization and Trinidad carnival: Diaspora, hybridity and identity in global culture. Cultural Studies, 13(4), 661690. doi:10.1080/095023899335095

Nurse, K. (2002). Bringing culture into tourism: Festival tourism and Reggae Sunsplash in Jamaica. Social and Economic Studies, 51, 127-143. Available at http://www.jstor.org/stable/27865264

Nurse, K. (2003). Festival tourism in the Caribbean: An economic impact assessment. Port of Spain, Trinidad and Tobago: Inter- 
American Development Bank.

Nurse, K. (2004). Reinventing CARIFESTA: A strategic plan. Georgetown, Guyana: Caricom Taskforce on CARIFESTA.

Nurse, K., Demas, A., Tull, J., Paddington, B., O'Young, W., Gray, M., Hoagland, H., \& Reis, M. (2007). The cultural industries in CARICOM. Bridgetown, Barbados: Caribbean Regional Negotiating Machinery.

Picard, D., \& Robinson, M. (2006). Remaking worlds: Festivals, tourism and change. In M. Robinson, \& D. Picard (Eds.), Festivals, Tourism and Social Change: Remaking worlds (Kindle ed., Ch. 1). Clevedon: Channel View.

Quinn, B. (2005). Arts festivals and the city. Urban Studies, 42(5/6), 927-943. doi: 10.1080/00420980500107250

Quinn, B. (2006). Problematising 'festival tourism': Arts festivals and sustainable development in Ireland. Journal of Sustainable Tourism, 14(3), 288-306. doi:10.1080/09669580608669060

Thompson, T. (2012, December 7). BTC pledges \$850,000 to Junkanoo Corporation. The Nassau Guardian. Retrieved from http://www.thenassauguardian.com/index.ph p?option $=$ com_content $\&$ view $=$ article $\& i d=3$ 5871\&Itemid $=27$
Tull, J. (2012). Gathering festival statistics: Theoretical platforms and their relevance to building a global rubric. Journal of Eastern Caribbean Studies, 37(3/4), 40-70.

United Nations Conference on Trade \& Development, \& United Nations Development Programme. (2008). Creative economy report 2008. Geneva, Switzerland: United Nations. Retrieved from http://unctad.org/en/Docs/ditc20082cer_en.p df

United Nations Conference on Trade \& Development, \& United Nations Development Programme. (2010). Creative economy report 2010. Geneva, Switzerland: United Nations. Retrieved from http://unctad.org/en/Docs/ditctab20103_en.p df

Vanderpool, J., \& Fielding, W. J. (2003). The postal survey as a research tool in New Providence. College of The Bahamas Research Journal, 12, 46-55. Retrieved from http://journals.sfu.ca/cob/index.php/files/arti cle/view/52/82

Yeoman, I., Robertson, M., Ali-Knight, J., Drummond, S., \& McMahon-Beattie, U. (Eds.). (2004). Festival and events management: An international arts and culture perspective. Burlington, MA: Elsevier.d. 